\title{
Which Parameters could be Useful for Predicting Malignancy in Solid Adnexal Masses?
}

\author{
Juan Luis Alcázar, Pedro Royo, Laura Pineda, Alvaro Ruiz-Zambrana, María Aubá, Begoña Olartecoechea \\ Department of Obstetrics and Gynecology, Clinica Universitaria de Navarra, University of Navarra, Pamplona, Spain
}

Correspondence: Juan Luis Alcázar, MD, Department of Obstetrics and Gynecology, Clinica Universitaria de Navarra Avenida Pio XII, 36, 31008 Pamplona, Spain

Phone: 34-948-255400, Fax: 34-948-296500, e-mail: jlalcazar@unav.es

\begin{abstract}
To determine which clinical, biochemical and other sonographic parameters could be useful to predict malignancy in sonographically solid adnexal masses.

Methods: Clinical (age, menopausal status, complaints and physical examination), biochemical (serum CA-125 levels) and other sonographic features (tumor volume, ascites, bilaterality, blood flow location and velocimetric pattern) from 163 women diagnosed as having a solid adnexal mass on B-mode gray-scale ultrasound were reviewed for this retrospective study. All patients had undergone surgery and mass removal. Definitive histologic diagnosis was available in all cases. All parameters were compared to final histological diagnosis (benign or malignant) in univariate statistical analysis. Then a stepwise forward logistic regression analysis was performed to identify those features that independently predict malignancy.
\end{abstract}

Results: A total of 173 masses were analyzed. Patients mean age was 52.4 years (range: 15 to 84 years) 117 masses were malignant and 56 were benign. After univariate analysis all parameters showed statistical differences between benign and malignant tumors. After logistic regression analysis only central blood flow (odd ratio: 64.2, 95\% CI: 17.07 to 242.03 ) and presence of ascites (odd ratio: 32.77, 95\% CI: 5.38 to 199.72 ) were identified as independent predictors of malignancy. The presence of one of these two features correlated to malignancy in $98.6 \%$ of cases. The absence of both was found in $82.1 \%$ of benign tumors.

Conclusions: The presence or absence of ascites or central blood flow may be helpful for discriminating benign from malignant solid adnexal masses.

Keywords: Adnexal mass, solid tumor, ovarian cancer, ultrasound.

\section{INTRODUCTION}

Solid adnexal masses constitute a diagnostic challenge for most sonologist and sonographers. ${ }^{1}$ Most of solid adnexal masses are malignant. ${ }^{2,3}$ However, still a percentage of these lesions are benign. ${ }^{4,5}$

In most studies involving the use of ultrasound for discriminating benign from malignant solid adnexal masses other factors such as clinical complaints, physical examination or other additional ultrasound findings have not been analyzed in detail.
In the present study we aimed to determine whether any clinical, biochemical or other sonographic parameter could be helpful for predicting malignancy in solid adnexal masses.

\section{MATERIAL AND METHODS}

In this retrospective study clinical, biochemical and sonographic data from 163 women diagnosed as having entirely solid adnexal mass on B-mode ultrasound at our institution between January 1998 and December 2006 were reviewed.

Diagnostic work-up for all patients included complete medical history, pelvic examination, and serum CA-125 levels determination, as well as an ultrasound evaluation.

Medical history focused on patient's complaints and menopausal status. These data were recorded as follows:

1. Patient's complaints: Asymptomatic. Symptoms nonsuggestive of ovarian cancer such as abdominal pain or abnormal uterine bleeding. Symptoms suggestive of ovarian cancer such as abdominal swelling, bloating and abdominal discomfort.

2. Menopausal status: Premenopasual or postmenopausal. Menopause was defined as one year of absence of menstruation in women older than 45 years.

Pelvic exam was performed by staff specialists in Obstetrics and Gynecology. Findings were stated as "inconclusive", when no reliable information could be obtained, "nonsuspicious", in the presence of a less than $8 \mathrm{~cm}$ maximum diameter adnexal mass, mobile at examination, of cystic or solid consistency but regular contours and no evidence of ascites, or "suspicious", in the presence of at least one of the following: fixed and/or irregular adnexal mass regardless the size, a size $>8 \mathrm{~cm}$, evidence of ascites.

Ultrasound evaluation was performed according to a predetermined protocol. ${ }^{6}$ Briefly, Once the endovaginal probe was gently inserted into the vagina, the uterus and adnexal regions were scanned. Special attention was paid to adnexal masses. Then, morphological evaluation was performed. Only tumors entirely solid (100\% solid appearance) at B-mode 
examination (Fig. 1) were included in this study. Tumor volume was estimated according to the prolate ellipsoid formula $(\mathrm{A} \times \mathrm{B} \times \mathrm{C} \times 0.5233)$ and expressed in milliliters. After morphological evaluation was performed, color Doppler gate (Doppler settings: frequency: $5 \mathrm{MHz}$, Power Doppler gain: 0.8, dynamic range: $20-40 \mathrm{~dB}$, edge: 1 , persistence: 2, color map: 5, gate: 2, filter: L1, PRF: $0.6 \mathrm{kHz}$ ) was activated to identify vascular color signals within the tumor. If blood flow was detected it was stated as "peripheral" (color signals at the periphery) (Fig. 2) or "central” (blood flow detected in central part) (Fig. 3). In tumors with both peripheral and central blood flow only central blood flow was used for analysis. Subjective amount of low was stated as scanty, moderate or abundant.

Once a vessel was identified by color Doppler pulsed Doppler gate was activated to obtain a flow velocity waveform $(\mathrm{FVW})$. Resistance index $[\mathrm{RI}=(\mathrm{S}-\mathrm{D}) / \mathrm{S}]$ and peak systolic

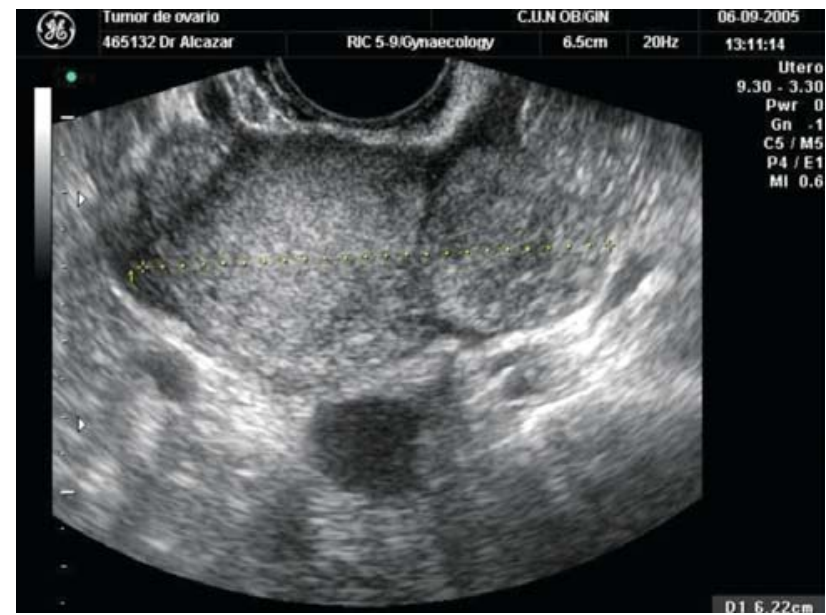

Fig. 1: B-mode transvaginal ultrasound from an entirely solid, bilobulated ednexal mass

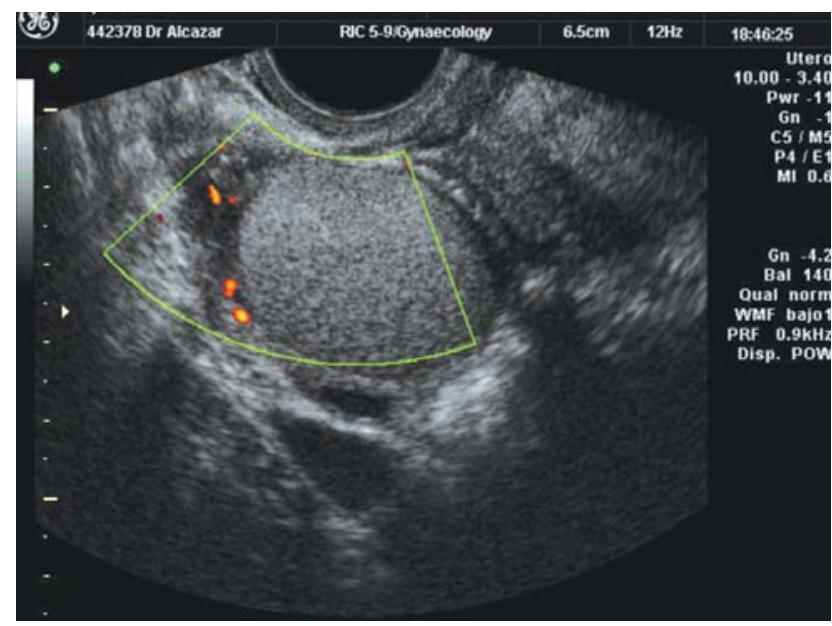

Fig. 2: Transvaginal power Doppler ultrasound showing a solid adnexal mass with peripheral blood flow

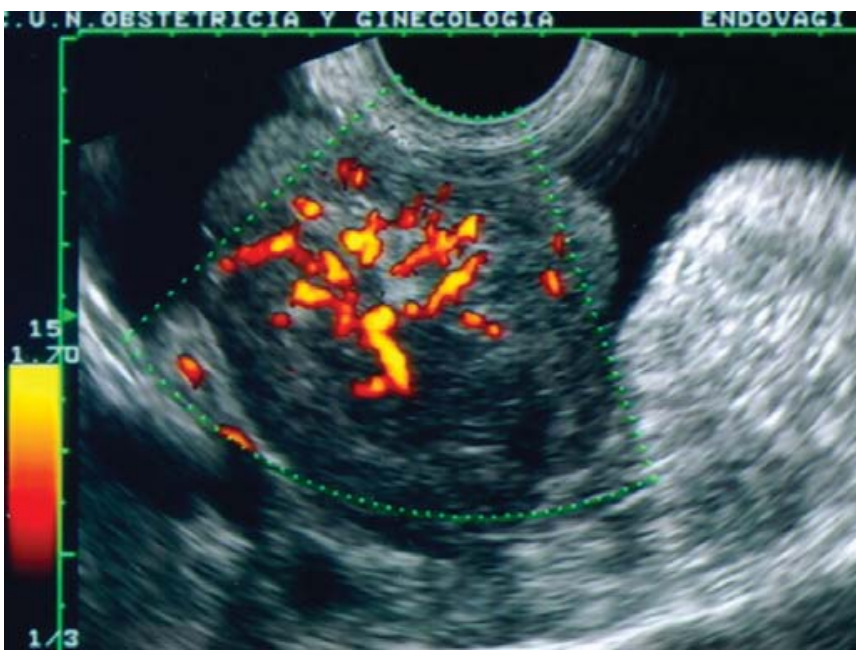

Fig. 3: Transvaginal power Doppler ultrasound showing a solid adnexal mass with central vascularization

velocity (PSV, $\mathrm{cm} / \mathrm{sec}$ ) were automatically calculated from at least three consecutive FVWs. In those tumors with more than one vessel the lowest RI and highest PSV found were used for analysis. Tumors were classified in four "velocimetric categories". ${ }^{7}$

- Low velocity/Low resistance (PSV $<10 \mathrm{~cm} / \mathrm{sec} / \mathrm{RI} \leq 0.45$ )

- Low velocity/High resistance (PSV $<10 \mathrm{~cm} / \mathrm{sec} / \mathrm{RI}>0.45$ )

- High velocity/High resistance (PSV $\geq 10 \mathrm{~cm} / \mathrm{sec} / \mathrm{RI}>0.45$ )

- High velocity/Low resistance (PSV $\geq 10 \mathrm{~cm} / \mathrm{sec} / \mathrm{RI} \leq 0.45$ )

All premenopausal women were evaluated in the follicular phase of the menstrual cycle.

The presence of other sonographic findings suggestive of malignancy such as bilaterality, ascites, peritoneal implants, "omental cake" and irregular mass contour were also recorded (Figs 4 to 6 ).

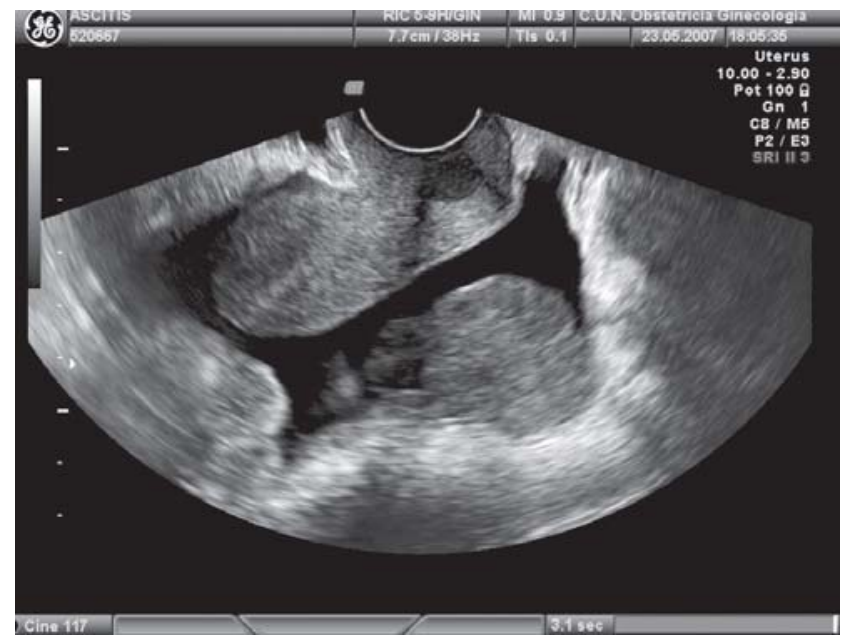

Fig. 4: B-mode transvaginal ultrasound depicting a solid adnexal mass and a significant amount of ascites 


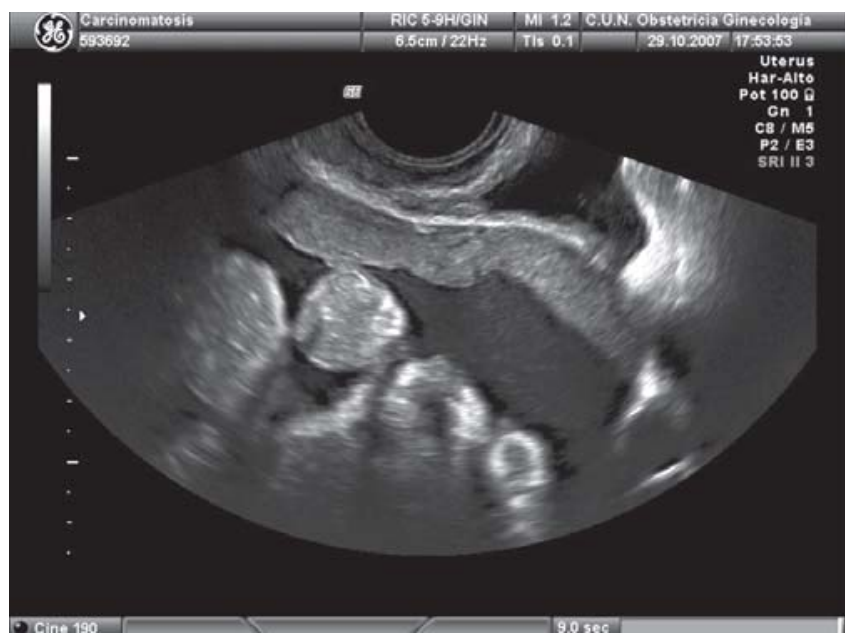

Fig. 5: B-mode transvaginal ultrasound showing a tumoral "plaque" over the vesicouterine peritoneum

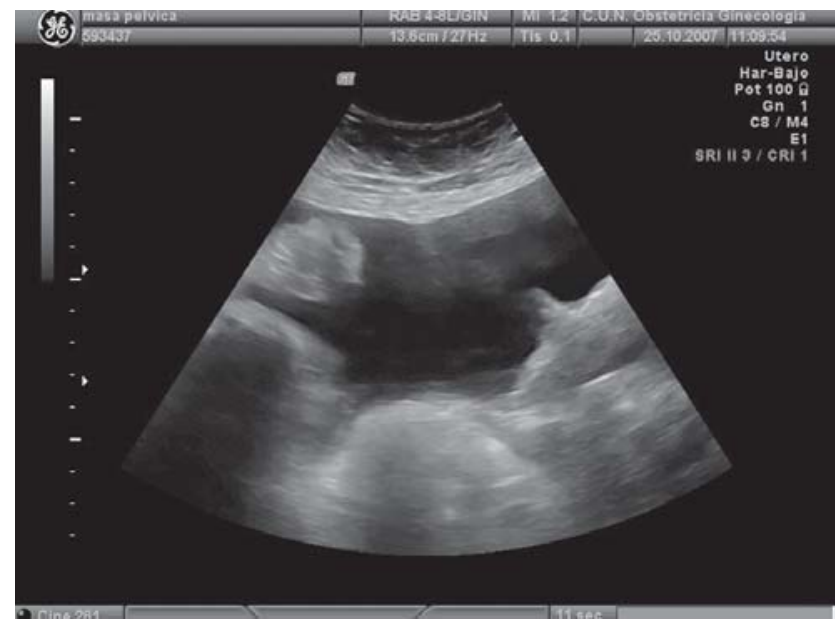

Fig. 6: Transabdominal ultrasound showing ascites and omental "cake"

In all cases the same day of ultrasound examination blood samples were collected to measure CA-125 plasma concentration. CA-125 measurements were performed using an enzyme-immunoassay with a monoclonal anitbody (CobasCore CA-125 II, Laboratories Roche, Basel, Switzerland). The sensitivity was $<5 \mathrm{UI} / \mathrm{mL}$. The intra- and interassay coefficients of variations were $<5.3 \%$ and $<7.5 \%$, respectively.

All tumors were surgically removed and definitive histological diagnosis obtained. Tumors were classified according to the World Health Organization. ${ }^{8}$ Ovarian malignancies were staged according to the FIGO. ${ }^{9}$ Low malignant potential tumors were considered as malignant.

\section{STATISTICAL ANALYSIS}

We performed first an univariate statistical analysis to find statistical differences in these parameters between malignant and benign tumors. The Kolmogorov-Smirnov test was used to assess normal distribution of continuous data. Continuous data were compared using the one-way ANOVA or U Mann-Whitney test, according to their distribution. Categorical variables were compared using the chi-square test for dichotomous variables and the Kendall's tau-b test for ordinal variables.

Once univariate analysis was done, we performed a multivariate forward stepwise logistic regression analysis (MLR) including as independent variables only those variables found to be statistically different between malignant and benign tumors in the univariate analysis and as dependent variable the final diagnosis (malignant or benign). This analysis allowed us to identify actual independent predictor of malignancy variables and to establish their individual importance calculating their respective odd ratios (ORs) with 95\% confidence intervals. The Hosmer-Lemeshow test was used to assess the goodness-to-fit of the model. ${ }^{10}$

A p value $\leq 0.05$ was considered as statistically significant. All statistical analyses were performed using the SPSS 15.0 statistical package (SPSS Inc, Chicago, Il).

\section{RESULTS}

- Ten women had bilateral solid masses, thus a total of 173 masses were evaluated.

- Patients' mean age was 52.2 years old, ranging from 15 to 84 years old.

- Sixty-seven (41\%) women were premenopausal and ninetysix (54\%) were postmenopausal.

- One hundred and seventeen (68\%) tumors were proved to be malignant and fifty-six (32\%) were benign (Table 1).

- On univariate analysis all parameters were statistically different between benign and malignant lesions (Table 2).

Table 1: Histologic diagnoses

\begin{tabular}{lrc}
\hline & $N$ & $\%$ \\
\hline Endometrioma & 2 & $1.2 \%$ \\
Teratoma & 19 & $11.0 \%$ \\
Ovarian cancer* & 78 & $45.1 \%$ \\
Cystadenofibroma & 2 & $1.2 \%$ \\
LMP carcinoma & 2 & $1.2 \%$ \\
Metastatic cancer** & 36 & $20.8 \%$ \\
Granulosa cell tumor & 2 & $1.2 \%$ \\
Tubo-ovarian abscess & 1 & $0.6 \%$ \\
Struma ovarii & 1 & $0.6 \%$ \\
Fibroma & 12 & $6.9 \%$ \\
Leiomyoma & 14 & $8.1 \%$ \\
Fibrothecoma & 1 & $0.6 \%$ \\
Brenner's tumor & 2 & $1.2 \%$ \\
Pelvic paraganglioma & 1 & $0.6 \%$ \\
\hline Total & 173 & $100.0 \%$ \\
\hline * Epithelial cancer: 74, Immature teratoma: 1, Primary lymphoma: 2, Sertoli- \\
leyding carcinoma:1. \\
** Origin: Stomach: 8, Colon-sigmoid: 7, Breast: 13, Uterine leiomiosarcoma: \\
2, Ureter: 1, Endometrium; 1, Liver: 1, Lung: 1.
\end{tabular}


Table 2: Univariate statistical analysis

\begin{tabular}{lccr}
\hline Parameter & $\begin{array}{c}\text { Benign } \\
(n=56)\end{array}$ & $\begin{array}{c}\text { Malignant } \\
(n=117)\end{array}$ & $P$ value \\
\hline Symptoms OC & $5.4 \%$ & $49.5 \%$ & $<0.001$ \\
Menopause & $39.2 \%$ & $69.2 \%$ & $<0.001$ \\
Suspicious physical exam & $17.9 \%$ & $69.2 \%$ & $<0.001$ \\
Median CA-125 (IU/mL) & 19.6 & 363.1 & 0.005 \\
& (IQR:2039.1) & $($ IQR: 19.6$)$ & \\
Median tumor volume (mL) & 84.2 & 75.9 & 0.348 \\
& $($ IQR: 246$)$ & $($ IQR: 157.2$)$ & \\
Ascites & $3.6 \%$ & $61.5 \%$ & $<0.001$ \\
Bilaterality & $3.6 \%$ & $23.4 \%$ & $<0.001$ \\
Central flow & $16.1 \%$ & $95.7 \%$ & $<0.001$ \\
Abundant flow & $12.5 \%$ & $67.6 \%$ & $<0.001$ \\
High PVS/Low RI & $19.6 \%$ & $58.1 \%$ & $<0.001$ \\
\hline
\end{tabular}

IQR: Interquartile range.

- However, after MLR analysis only ascites and central blood flow were determined as independent predictors for malignancy (Table 3).

- Both parameters were present in $98.3 \%$ of malignant tumors, whereas both were absent in $82 \%$ of benign tumors (Table 4).

Table 3: Multivariate logistic regression analysis

\begin{tabular}{llll}
\hline Parameter & Coefficient & OR $(95 \%$ CI $)$ & $P$ \\
\hline Ascites & 4.163 & $32.77(5.38$ to 199.72$)$ & $<0.0001$ \\
Central flow & 3.490 & $64.20(17.07$ to 242.03$)$ & $<0.0001$ \\
\hline
\end{tabular}

Hosmer-Lemeshow test: $\mathrm{P}=0.707$

OR: Odds ratio

Table 4: Correlation between predictor parameters and final histology

\begin{tabular}{lcccc}
\hline & & \multicolumn{2}{c}{ Histology } & Total \\
\cline { 3 - 5 } & & Malignant & Benign & Malignant \\
\hline $\begin{array}{l}\text { Ascites and } \\
\text { central blood } \\
\text { flow present }\end{array}$ & $\mathrm{N}$ & 115 & 10 & 125 \\
$\begin{array}{l}\text { Ascites and } \\
\text { central blood flow } \\
\text { absent }\end{array}$ & $\mathrm{N}$ & 2 & 46 & 48 \\
\hline Total & $\mathrm{N}$ & $1.7 \%$ & $82.1 \%$ & \\
\hline
\end{tabular}

\section{DISCUSSION}

The presence of a solid adnexal mass on B-mode ultrasound use to rise the suspicious of malignancy.

Several studies have demonstrated that solid components within a cystic mass or a mostly solid tumor are among the most significant predictors of malignancy. ${ }^{11-13}$

However, it is also well known that some benign ovarian tumors exhibit an entirely solid appearance of B-Mode ultrasound. ${ }^{14}$ When facing with a solid adnexal mass the differential diagnosis should be established between those lesions from ovarian origin, benign or malignant, and other lesions from extraovarian origin, such as benign uterine leiomyoma or cancers from other origin. ${ }^{15}$

Pedunculated uterine leiomyomas can be easily recognized when both ovaries are identified independently from the tumor and the tumor is seen arising from the uterine wall. ${ }^{16}$ However, other kinds of ovarian tumors are truly difficult to accurately identify. ${ }^{17}$

Studies focusing on solid adnexal or pelvic masses are scanty. ${ }^{18,19}$ Some authors have reported that clinical assessment may be useful for the differential diagnosis. ${ }^{15}$ However, many women present asymptomatic and the tumors are accidentally found out during routine examination. Furthermore, in our study patients' complaints were not an independent predictor for malignancy after multiple logistic regression analysis.

Our study confirms the relatively high prevalence of benign lesions that appear as solid tumors on B-mode ultrasound. In the present study we found that the association of ascitis and central vascularization in solid tumors is highly predictive of malignancy, whereas the absence of both features is related to benignity. These findings were rather not surprising but for the first time they are confirmed in a multivariate analysis in a relatively large series of solid adnexal masses.

A recent retrospective study from the IOTA group found out similar findings than our study. In this study the presence of an irregular solid tumor was associated with malignancy with a positive likelihood ratio of 37.2, as well as it was the presence of ascitis (positive likelihood ratio: 14.52). ${ }^{20}$

In conclusion, the presence or absence of ascites and central blood flow may be helpful for discriminating benign from malignant solid adnexal masses.

\section{REFERENCES}

1. Funt SA, Hann LE. Detection and characterization of adnexal masses. Radiol Clin North Am. 2002;40:591-608.

2. Guerriero S, Alcazar JL, Coccia ME, Ajossa S, Scarselli G, Boi M, Gerada M, Melis GB. Complex pelvic mass as a target of evaluation of vessel distribution by color Doppler sonography for the diagnosis of adnexal malignancies: results of a multicenter European study. J Ultrasound Med. 2002;21:1105-11.

3. Brown DL, Doubilet PM, Miller FH, Frates MC, Laing FC, DiSalvo DN, Benson CB, Lerner MH. Benign and malignant ovarian masses: selection of the most discriminating gray-scale and Doppler sonographic features. Radiology. 1998;208:10310 .

4. Guerriero S, Ajossa S, Garau N, Piras B, Paoletti AM, Melis GB. Ultrasonography and color Doppler-based triage for adnexal masses to provide the most appropriate surgical approach. Am J Obstet Gynecol. 2005;192:401-06.

5. Alcázar JL, Royo P, Jurado M, Mínguez JA, García-Manero M, Laparte C, Galván R, López-García G. Triage for surgical management of ovarian tumors in asymptomatic women: 
assessment of an ultrasound-based scoring system. Ultrasound Obstet Gynecol 2008;32:220-25.

6. Alcázar JL, Ruiz-Perez ML, Errasti T. Transvaginal color Doppler sonography in adnexal masses: which parameter performs best? Ultrasound Obstet Gynecol 1996;8:114-19.

7. Alcázar JL, Mercé LT, Laparte C, Jurado M, López-García G. A new scoring system to differentiate benign from malignant adnexal masses. Am J Obstet Gynecol. 2003;188:685-92.

8. Serov SF, Scully RE, Sobin LH: International histological classification of tumors. No 9, Histological typing of ovarian tumors, World Health Organization, Geneva, 1973.

9. Sheperd JH: Revised FIGO staging for gynecological cancer. Br J Obstet Gynecol 1989; 96: 889-92.

10. Hosmer DW, Lemeshow S. Applied Logistic Regression. New York, Willey-Interscience 1989.

11. Tailor A, Jurkovic D, Bourne TH, Collins WP, Campbell S. Sonographic prediction of malignancy in adnexal masses using multivariate logistic regression analysis. Ultrasound Obstet Gynecol 1997;10:41-47.

12. Alcázar JL, Errasti T, Laparte C, Jurado M, López-García G. Assessment of a new logistic model in the preoperative evaluation of adnexal masses. J Ultrasound Med. 2001;20:84148.

13. Schelling M, Braun M, Kuhn W, Bogner G, Gruber R, Gnirs J, Schneider KT, Ulm K, Rutke S, Staudach A. Combined transvaginal B-mode and color Doppler sonography for differential diagnosis of ovarian tumors: results of a multivariate logistic regression analysis. Gynecol Oncol. 2000;77:78-86.

14. Joshi M, Ganesan K, Munshi HN, Ganesan S, Lawande A. Ultrasound of adnexal masses. Semin Ultrasound CT MR. 2008;29:72-97.

15. Brown DL. A practical approach to the ultrasound characterization of adnexal masses. Ultrasound Q. 2007;23:87105.

16. Sladkevicius P, Valentin L, Marsál K. Transvaginal Doppler examination for the differential diagnosis of solid pelvic tumors. J Ultrasound Med. 1995;14:377-80.

17. Valentin L, Ameye L, Jurkovic D, Metzger U, Lécuru F, Van Huffel S, Timmerman D. Which extrauterine pelvic masses are difficult to correctly classify as benign or malignant on the basis of ultrasound findings and is there a way of making a correct diagnosis? Ultrasound Obstet Gynecol. 2006;27:438-44.

18. Bret PM, Guibaud L, Atri M, Gillett P, Seymour RJ, Senterman MK. Transvaginal US-guided aspiration of ovarian cysts and solid pelvic masses. Radiology. 1992;185:377-80.

19. Valentin L. Use of morphology to characterize and manage common adnexal masses. Best Pract Res Clin Obstet Gynaecol. 2004;18:71-89.

20. Timmerman D, Testa AC, Bourne T, Ameye L, Jurkovic D, Van Holsbeke C, Paladini D, Van Calster B, Vergote I, Van Huffel S, Valentin L. Simple ultrasound-based rules for the diagnosis of ovarian cancer. Ultrasound Obstet Gynecol. 2008;31:681-90. 